Measurement of turbulence using

SAR

\title{
Measurement of turbulence in the oceanic mixed layer using Synthetic Aperture Radar (SAR)
}

S. G. George and A. R. L. Tatnall

Astronautics Research Group, Faculty of Engineering \& the Environment, University of Southampton, Southampton, UK

Received: 25 June 2012 - Accepted: 26 August 2012 - Published: 13 September 2012

Correspondence to: S. G. George (sgg303@ soton.ac.uk)

Published by Copernicus Publications on behalf of the European Geosciences Union.

Title Page

Abstract Introduction

Conclusions

References

Tables

Figures

14

4

Back

Close

Full Screen / Esc

Printer-friendly Version

Interactive Discussion 


\section{Abstract}

Turbulence in the surface layer of the ocean contributes to the transfer of heat, gas and momentum across the air-sea boundary. As such, study of turbulence in the ocean surface layer is becoming increasingly important for understanding its effects on climate 5 change. Direct Numerical Simulation (DNS) techniques were implemented to examine the interaction of small-scale wake turbulence in the upper ocean layer with incident electromagnetic radar waves. Hydrodynamic-electromagnetic wave interaction models were invoked to demonstrate the ability of Synthetic Aperture Radar (SAR) to observe and characterise surface turbulent wake flows. A range of simulated radar images are 10 presented for a turbulent surface current field behind a moving surface vessel, and compared with the surface flow fields to investigate the impact of turbulent currents on simulated radar backscatter. This has yielded insights into the feasibility of resolving small-scale turbulence with remote-sensing radar and highlights the potential for extracting details of the flow structure and characteristics of turbulence using SAR.

\section{Introduction}

The boundary between the air and the sea plays a crucial role in regulating the thermal and gaseous balance between ocean and atmosphere. Turbulence and mixing in the near-surface layer of the ocean have considerable impact on the transfer of properties such as heat and momentum across this boundary. There is currently increasing interest in the effect of the upper ocean layer on climate change studies, particularly in the role of ocean turbulence in the exchange of carbon dioxide between air and sea: it is estimated that $25-50 \%$ of anthropogenic $\mathrm{CO}_{2}$ delivered into the air across the globe is absorbed by the sea (Sabine et al., 2004; Khatiwala et al., 2009) and that upper ocean turbulence may play a key role in this exchange (Soloviev et al., 2007). The rates of exchange of such properties are governed by the characteristics and dynamics of the ocean surface boundary layer (and, likewise, the marine atmospheric boundary layer).
OSD

9, 2851-2883, 2012

Measurement of turbulence using SAR

S. G. George and A. R. L. Tatnall

\section{Title Page}

Abstract Introduction

Conclusions

Tables

References

Figures

14

$>$ I

4

Back

Close

\section{Full Screen / Esc}

Printer-friendly Version

Interactive Discussion 
Such conditions are dependent on the surface wave system and fluid mixing, and therefore near-surface turbulence is therefore a critical element in the exchange processes of gas, heat and momentum between the ocean and atmosphere (McKenna, 2000; McKenna and McGillis, 2004; Soloviev et al., 2007; Zappa et al., 2009; Veron et al., 5 2011). Identifying methods by which turbulent phenomena can be observed and levels of small-scale turbulence in the oceanic mixed layer may be identified through remotesensing techniques could be of benefit in quantifying the impact of the ocean mixed layer on climate change, and improving understanding of this complex system.

Turbulence is present in the ocean over a broad spectrum of spatial scales, from 10 mesoscale and geostrophic eddies formed by global currents to small-scale turbulence generated by breaking surface- or internal waves. Synthetic Aperture Radar (SAR) has shown considerable ability to remotely observe a wide range of such phenomena as shown by, for example, Chubb et al. (1999), Ivanov and Ginzburg (2002), Alpers et al. (2004) and Johannessen et al. (2005). Turbulent processes in the upper ocean 15 layer predominantly affect SAR signatures in two ways: firstly, the primary flow structure and currents propagating to the surface produce wave-current interactions which cause straining of the surface distribution of short wind waves. Hence, features such as internal waves can be resolved due to their surface currents modifying the distribution of Bragg waves (Thompson, 1985), as well as other oceanic phenomena. Secondly, fine-scale turbulence, velocity fluctuations and viscosity near the surface layer act to redistribute surface wave energy at scales on the order of the radar wavelength, through the processes of viscous dissipation and downward convection of wave energy (Kitaigorodskii and Lumley, 1983; Kitaigorodskii et al., 1983; Reed et al., 1990; Ölmez and Milgram, 1992; True et al., 1993). Turbulence and mixing at, and near, the sea surface is therefore typically observed as a region of reduced radar backscatter, with the dissipation of wave energy causing a reduction of the root mean square (rms) amplitude of Bragg-scattering waves and a dampening of surface roughness. Particularly in the case of ship wakes, turbulence is also associated with energetic surface mixing that causes surfactant materials to accumulate at the sea surface and generate further
OSD

9, 2851-2883, 2012

Measurement of turbulence using SAR

S. G. George and A. R. L. Tatnall

Title Page

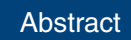

Introduction

Conclusions

Tables

References Figures

14

4

Back

Close

Printer-friendly Version

Interactive Discussion 
dampening of short waves. The result is reduced backscattering and increased levels of specular reflection in regions of turbulence, leading to dark patches in Normalised Radar Cross-Section (NRCS) and SAR imagery. Interaction of the surface flow with the incident wind and wave systems also produces short-wave interaction, creating 5 a complex pattern of bright and dark regions of NRCS. The importance of near-surface fluid motions on air-sea exchange processes and the ability of such motions to modify the response of remote-sensing radar lead to encouraging potential for improving understanding of the oceanic mixed layer from remote measurements.

Moving surface vessels such as ships typically produce wakes which are highly vis10 ible in ocean SAR images, where the region behind the vessel displays a region of wake turbulence and surface currents which produce a visible backscattering response. A schematic of a typical ship wake is presented in Fig. 1, and examples of turbulent wake features in operational SAR images can be found extensively in the literature (Munk et al., 1987; Lyden et al., 1988; Milgram et al., 1993; Hennings et al., 1999; 15 Toporkov et al., 2011). Simulation of ship-wake turbulence and the NRCS response has previously been studied by, for example, Reed et al. (1990), True et al. (1993) and Fujimura et al. (2011). There has, however, been limited investigation on the impact of turbulence on short surface waves. A further challenge is that the presence of surfactants and oil films floating on the sea surface can often disguise the effect of turbulence due to their greater dampening impact on radar-scattering waves. The development of high-resolution SARs such as TerraSAR-X has reinvigorated the interest in identifying small-scale ocean processes from remote observations, leading to recent studies of turbulent ship wakes such as Soloviev et al. (2010), Fujimura et al. (2011) and Toporkov et al. (2011). These investigations indicate that with improvement in signal-to-noise capability and spatial resolution of future SAR instrumentation, increased discrimination of low-backscatter features such as patches of near-surface turbulence may be improved. This paper discusses the results of research into the observation of wake turbulence and turbulent structure in the upper layer of the ocean by SAR and the potential for extraction of such characteristics from simulated radar imagery.
OSD

9, 2851-2883, 2012

Measurement of turbulence using SAR

S. G. George and A. R. L. Tatnall

Title Page

Abstract Introduction

Conclusions

Tables References Figures

14

4

Back

Close

Printer-friendly Version

Interactive Discussion 


\section{Simulation of wake turbulence and remote-sensing signatures}

In order to examine the effect of upper ocean turbulence on radar images, a simulation procedure was constructed using a case study of a simple moving surface vessel acting as an initiator for turbulence near the fluid surface. The region aft of such a body dis5 plays a rearward wake containing regions of intense turbulence and vortical flow, and Direct Numerical Simulation (DNS) techniques were integrated with an ocean radar imaging model to numerically simulate turbulence near a fluid surface and derive theoretical remote-sensing signatures. The process of translating results from turbulent simulation by DNS to simulated surface signatures in NRCS arising from the turbulent flow is presented in Fig. 2.

The DNS process was performed using a $\mathrm{C} / \mathrm{C}++$ numerical code solving the incompressible Navier-Stokes equations for fluid velocity, $u_{i}$, given in Cartesian tensor notation by

$\frac{\partial u_{i}}{\partial t}+u_{j} \frac{\partial u_{i}}{\partial x_{j}}=-\frac{1}{\rho} \frac{\partial p}{\partial x_{i}}+v \frac{\partial^{2} u_{i}}{\partial x_{j} \partial x_{j}}+F_{i}$

15 where $i=(1,2,3), \rho$ is the fluid density, $v$ is the kinematic viscosity, $t$ represents time, $F_{i}$ represent external forcing terms, $p$ is the fluid pressure and $u_{i}=(u, v, w)$ represents velocity in the coordinate system $x_{i}=(x, y, z)$. Simulations were performed using the IRIDIS3 high-performance computing facility at the University of Southampton. The algorithm solves with sufficient numerical accuracy to represent all turbulence scales (Thomas and Williams, 1997; Archer, 2008). Modelling of a representative surface body was applied through body-force parameterisation using an immersed boundary method, and a non-dimensional freestream velocity, $U$, applied in the $x$-direction to mimic the body moving in a fixed reference frame. The vessel was characterised by a submerged half-sphere, where $F_{i}$ are the external body forces due to the virtual body surface $\mathbf{B}=\left(B_{x}, B_{y}, B_{z}\right)$. The submerged half-sphere was modelled using a semi-spherical virtual body surface with no thrust component, leading to a modelled
OSD

9, 2851-2883, 2012

Measurement of turbulence using SAR

S. G. George and A. R. L. Tatnall

Title Page

Abstract Introduction

Conclusions

Tables

References

Figures

14

4

Back

Close

Full Screen / Esc

Printer-friendly Version

Interactive Discussion $\rightarrow 1$

$>$

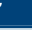

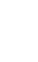

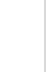

.

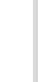


representation of a towed surface vessel. The no-slip boundary condition was applied to the embedded surface. A schematic of the DNS domain and parameterisation of the body is shown in Fig. 3. No efforts to replicate the profile of any existing surface vessel were made, and the simulation also neglects other features of the wake presented in 5 Fig. 1, such as the Kelvin and transverse wave systems and the occurrence of breaking waves. The wake is hence simulated as a region of drag behind the body which causes the flow to decelerate and generate a region of mixing and vorticity, and a turbulent wake analogous to that of a surface moving vessel. A representative output from the DNS process is shown in Fig. 4, showing an isosurface of the second invariant of 10 the velocity gradient tensor $(\Pi)$, which is a useful visual marker for turbulent structure and vorticity.

The three-dimensional domain was formed of approximately 70 million grid points: 2112 in the $x$-direction (direction of vessel motion), 256 in the $y$-direction (perpendicular to vessel motion in surface plane), and 128 in the $z$-direction (vertical direction); 15 a schematic of this domain is presented in Fig. 3. A fixed boundary (under the rigidlid approximation) was applied to the upper surface and periodic boundary conditions applied to the edges of the domain. The numerical flow was processed until the onset of fully-developed turbulence; at desired time steps, pausing the simulation to write to disk the velocity $\left(u_{i}\right)$ and pressure $(p)$ data at each grid point in the domain. The three-dimensional velocity data was then retrieved, returned to dimensional form and exported to the radar image model to simulate modulation of the surface wave spectrum due to turbulent currents, and subsequently to derive simulated NRCS imagery. The reference frame was adjusted to remain fixed with respect to the fluid, creating a turbulent wake equivalent to a simulated vessel moving over a stationary water sur25 face.

The radar ocean imaging modelling process consists of two phases: firstly, calculating the modulation of the ambient wave system in the presence of disturbing surface currents (in this case, the turbulent flow), and secondly, approximating the radar backscattering response from the ocean surface based on the modulated wave
OSD

9, 2851-2883, 2012

Measurement of turbulence using SAR

S. G. George and A. R. L. Tatnall

\section{Title Page}


spectrum. The radar ocean imaging model employed in the study was the M4S Toolkit v3.2.0 (hereby referred to as "M4S"). A complete theory of the model may be found in Romeiser et al. (1997) and Romeiser and Alpers (1997); its operation is summarised here. Since it is a quantity conserved by an ocean wave system in the presence of the 5 surface currents, wave action spectral density is commonly computed in wave-current interaction models to examine the distribution of surface backscattering waves (Phillips, 1966). The M4Sw320 algorithm of M4S approximates modulation of the wave spectrum due to the surface wake profile and specification of a characteristic wind field present at reference height $10 \mathrm{~m}$ above the simulated ocean surface. In all cases, a uniform 10 wind field was applied to the domain with varying magnitude and direction applied in different tests. The wave spectral data is then exchanged with the radar simulation module M4Sr320 of M4S to approximate the radar backscattering response based on the modulated surface, specified radar instrument parameters and the desired observation geometry. Specification of the radar operating frequency $f_{0}(\mathrm{GHz})$, incidence 15 angle $\theta_{0}$ (degrees), instrument polarisation $(\mathrm{HH} / \mathrm{HV} / \mathrm{VH} / \mathrm{VV})$, and look direction with respect to the $x$-axis (defined in degrees) are required in the M4S batch file to compute the NRCS backscatter response. The algorithm is described by the Two-Scale Model formulation of Wright (1968), upon which the Bragg NRCS contribution to radar backscatter, $\sigma_{0, \text { Bragg }}$, is proportional to the wave height spectral density $\psi(\boldsymbol{k})$ of waves 20

$\boldsymbol{k}_{\mathrm{B}}=2 \boldsymbol{k}_{0} \sin \theta_{0}$

$\boldsymbol{k}_{0}=\frac{2 \pi f_{0}}{c}$

where $\boldsymbol{k}_{0}$ denotes the radar wavenumber vector and $c$ is the speed of light. Addi25

tional contribution to the NRCS is provided by the orientation of the backscattering wave to the horizontal based on the tilting angle of the long surface waves, forming the two-scale contribution to NRCS of both long- and short-wave components. The
OSD

9, 2851-2883, 2012

Measurement of turbulence using SAR

S. G. George and A. R. L. Tatnall

Title Page

Abstract Introduction

Conclusions

Tables

References

Figures

14

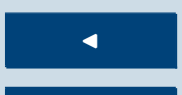

Back

Close

Printer-friendly Version

Interactive Discussion 
backscattering response of Bragg waves only is referred to here as the Bragg NRCS $\sigma_{0, \text { Bragg }}$, whereas the two-scale response is the composite spectrum NRCS, $\sigma_{0}$.

\section{Comments}

There remain some comments regarding the consistency of the modelling and simula5 tion techniques used in this research and the characteristics of small-scale turbulence, which are raised here.

Turbulence of a fluid, particularly at small scales near the ocean surface, implies a rapid fluctuation of quantities over small spatial distances. Turbulence is thus by a highly-energetic state of mixing, and one which may be characterised by changes of high gradients of velocity at small scales. Typical radar ocean imaging algorithms use the theory of weak hydrodynamic interactions in order to process modulated wave spectra using the conservation of wave action spectral density (LeBlond and Mysak, 1978). This theory, within the framework of Geometrical Optics under the WKB approximation assumes that disturbances in surface current are small when compared to the primary ocean wavelengths, and that the current field can be assumed to stationary as waves propagate through it. Hence, these assumptions are an oversimplification in cases where there are very strong gradients in the surface current, and therefore there may be substantial modulation of some waves that nonlinearities occur that are not represented correctly in the specified wave energy balance. Time scales of current variation must not be so rapid that many wave components feel current changes and acceleration as they navigate the current field: in this turbulent case, there may be, locally, rapid fluctuation of velocity at small scales even though the mean surface current (at the longer length scales) may be assumed to be slowly-varying in time in comparison with the wave's journey across the domain. The mean current may therefore be 25 considered stationary or "frozen" as wave propagation is calculated, and application of hydrodynamic wave interaction techniques may be justified.

The case study of turbulent wake flow considers currents in the mixed layer due to the turbulence and vorticity generated by near-surface body forces, analogous to

\section{8}

OSD

9, 2851-2883, 2012

Measurement of turbulence using SAR

S. G. George and A. R. L. Tatnall

Title Page

Abstract Introduction

Conclusions

Tables

References

Figures

14

4

Back

Close

Printer-friendly Version

Interactive Discussion 
presence of a moving surface vessel. The interaction of turbulence and waves may be considered weak if the energy gained by the turbulence through interaction with waves is small when compared with the energy transfer due to internal turbulence interactions. Hence, the accuracy of the simulation may be improved by including in the wave action 5 conservation calculation the effects of exchange of energy between the turbulence and the wave system: some authors have operated models which directly represent turbulent energy dissipation (spectral modification caused by turbulent fluctuations within the wake), such as Milgram et al. (1993) and True et al. (1993). In the discussion presented in this paper, the effects of turbulent dissipation of short-wave energy have not been 10 accounted for in the calculation of the modulated wave spectrum. Results presented by Ölmez and Milgram (1992) indicate that energy dissipation due to turbulent fluctuations may be significant for regions of intense small-scale mixing (particularly ship wakes), and thus examination of the effect of dissipation of wave energy by subsurface turbulence on SAR remote-sensing signatures should be applied in future numerical 15 work.

Simulation of turbulent ship wakes has been studied extensively in the literature by a range of authors using radar/hydrodynamic interaction theory (Lyden et al., 1985; True et al., 1993; Reed and Milgram, 2002). There is limited discussion of the impact of the turbulent wake flow on the applicability of the governing equations operated by radar ocean imaging models, however many researchers have successfully applied such methods to wake turbulence, including turbulence at small scales in the far wake of a ship (Fujimura et al., 2011). Since the large-scale turbulent motions may be considered as "slowly-varying" when compared to the surface wave field, and the small-scale turbulent motions (when averaged) do not affect the larger picture, it may be assumed that the wave action computation provides a reasonable approximation of the wave-current interaction process. Therefore, the defined strategy was applied in this case study of the interaction of surface-layer turbulence with wave spectra for remote-sensing application.
OSD

9, 2851-2883, 2012

Measurement of turbulence using SAR

S. G. George and A. R. L. Tatnall

Title Page

Abstract Introduction

Conclusions

Tables

References

Figures

14

4

Back

Close

Printer-friendly Version

Interactive Discussion 


\section{Results and discussion}

The full simulation strategy integrating DNS and hydrodynamic/electromagnetic wave modelling to simulate backscatter responses of surface wake turbulence was performed to examine radar signatures under a range of conditions. A selection of the 5 obtained results are presented here. A key focus of the study was to examine the feasibility for extracting information on the structure of near-surface fluid turbulence using remote-sensing instrumentation. Therefore, experiments primarily focussed on the visibility of such structure from simulated Bragg NRCS and composite spectrum NRCS backscatter imagery.

\subsection{Observation of turbulent surface structure}

A representative plot of a region of the wake commencing approximately $130 \mathrm{~m}$ aft of the vessel, rendered in $5.3 \mathrm{GHz}$ (C-band) composite spectrum NRCS at $23^{\circ}$ incidence and $\mathrm{HH}$-polarisation, is presented in Fig. $5 \mathrm{a}$. The surface $u$ - and $v$-velocity profiles for this region of the wake are shown in Fig. $5 \mathrm{~b}, \mathrm{c}$, respectively. The wake profile is 15 formed of a domain 1000 grid points long in the $x$-direction, and 250 points in the $y$-direction. Peak currents in the turbulent region are observed to be in the region of $0-0.1 \mathrm{~m} \mathrm{~s}^{-1}$ in magnitude, as shown by Fig. $5 \mathrm{~d}$. Qualitative comparisons may be drawn between the surface velocity profiles and the modulated NRCS response; in particular, the influence of velocity gradients and fluctuations on the observed NRCS distribution, and how details of the flow structure present in the surface velocity profiles can be resolved by the simulated radar. The NRCS modulation responds to current patterns within the wake arising from fluctuations of the turbulent flow (due to wave-current interaction), hence permitting the surface flow structure of the wake to be observed and identified. Such structure is illustrated by the distribution of flow currents and hence the
OSD

9, 2851-2883, 2012

Measurement of turbulence using SAR

S. G. George and A. R. L. Tatnall

\section{Title Page}

Abstract Introduction

Conclusions

Tables References Figures

14 DI

4

Back

Close

\section{Full Screen / Esc}

Printer-friendly Version

Interactive Discussion 
Fujimura et al. (2011), showing similar instances of the velocity structure of turbulence propagating through the simulated radar imaging process into modulated NRCS.

A portion of the wake approximately $205-245 \mathrm{~m}$ aft of the surface vessel for a simulated $5.3 \mathrm{GHz}$ (C-band) radar is depicted in Fig. 6, where 6a displays the Bragg NRCS

5 response, $6 \mathrm{~b}$ the composite spectrum NRCS response, and $6 \mathrm{c}$, d, e represent the surface $u$-velocity, $v$-velocity and vorticity, respectively. Details of the flow structure present in the velocity data can be resolved in the NRCS responses, particularly the relationship between the composite spectrum NRCS and the spanwise $v$-velocity highlighting interaction with wind in the $y$-direction: this can be observed on the upper and lower 10 edges of the wake where there is interaction between the wake velocity, the ambient wind and the quiescent fluid outside the wake. It is also encouraging that characteristics of the internal flow structure, i.e. the velocity fluctuations along the centre line of the wake axis, produce modulation of the surface wave spectrum and are resolved in the NRCS response. Kelvin-Helmholtz billows arising from shear instability within the wake 15 flow can also be observed in the DNS velocity and vorticity data, visible as unstable fluctuations in the surface flow characteristics at the edges of the wake region in Figs. $6 c-e$. These effects propagate through the integrated hydrodynamic-electromagnetic modelling process, and can be observed in the in simulated Bragg and composite spectrum NRCS images, such as in Figs. 6a-b.

20 The results obtained here indicate that, where present, characteristics of the smallscale turbulent flow structure in a surface wake propagates through the process of calculating wave-current interaction, and are thus rendered visible in NRCS. This demonstrates that the wake flow has measurable influence the NRCS response, and this may be developed further to understand more about the relationship between near-surface

\subsection{Instrument frequency}

Since Bragg NRCS is proportional to the wave height spectral density of waves at Bragg wavenumber $\boldsymbol{k}_{\mathrm{B}}$ according to Eq. (2) and the effect of wave-current interaction

OSD

9, 2851-2883, 2012

Measurement of turbulence using SAR

S. G. George and A. R. L. Tatnall

Title Page

Abstract Introduction

Conclusions

Tables References Figures

14
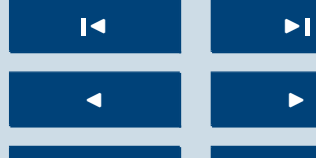

Back

Close

Printer-friendly Version

Interactive Discussion 
on wave height spectral density is not constant across the spectrum, the backscattering response may display significant variation of NRCS with $\boldsymbol{k}_{\mathrm{B}}$. Changes in $\boldsymbol{k}_{\mathrm{B}}$ are applied here by altering the operating frequency according to Eqs. (2)-(3), while keeping fixed the incidence angle of the instrument. Perturbing the operating frequency 5 of the simulated instrument used to generate the NRCS response therefore has the ability to alter the distribution of the Bragg-scale waves primarily responsible for radar backscatter and hence the composition of turbulent flow structure that is translated to NRCS. Figures 7, 8 depict a portion of the wake approximately 165-205 $\mathrm{m}$ aft of the surface vessel rendered in Bragg NRCS at X-, C-, S- and L-band plotted on the same 10 colour axis. These simulations assume constant parameters for $\mathrm{HH}$-polarisation, $23^{\circ}$ angle of incidence and a look direction in the positive $y$-direction. A line is drawn at a position approximately $170 \mathrm{~m}$ to depict the location of transects taken of the Bragg NRCS across the wake: varying the operating frequency reveals differing effects of the flow structure at different regions of the surface wave spectrum, highlighting different 15 areas of primary modulation. Presented in Fig. 9 is a composite plot of transects of Bragg NRCS at the frequencies applied in Figs. 7, 8. These results prove that modulation of the surface wave spectrum is dependent on the operating radar wavenumber and that the visibility of small-scale features on the surface may vary considerably with operating frequency. There is also variation in the resolved modulation depth (variation between maximum and minimum NRCS values), and mean NRCS (average across the image) value, both of which may influence the desired operating frequency to maximise the ability to resolve small-scale turbulent features. While the S-band plot of Fig. 8a displays the largest average NRCS across the image (which may be important in presence of signal-to-noise losses), the C-band simulation displayed in Fig. 7b displays the largest range of NRCS across the applied transect, allowing the potential to extract more variation in structure. This could promote the use of multi-frequency instruments to observe the ocean to obtain a more rounded view of the surface, and improve understanding small-scale surface flow features.
OSD

9, 2851-2883, 2012

Measurement of turbulence using SAR

S. G. George and A. R. L. Tatnall

Title Page
Full Screen / Esc

Printer-friendly Version

Interactive Discussion 


\subsection{Viewing orientation}

Since the backscattering response primarily captures Bragg-scale waves travelling toward/away from the instrument look direction, there is an associated directionality of the modulated wave spectrum which can be observed by rotating the instrument orien5 tation with respect to both the centre axis of the wake and the direction of the applied wind field. This has the potential to reveal further information about the character of the turbulent flow from NRCS images viewed from varying perspectives; observed in Fig. 10, where the impact of varying the instrument look direction from 10a $0^{\circ}$ (aligned with the $x$-direction) to $10 \mathrm{~d} 90^{\circ}$ (aligned with the $x$-direction) on the resolved structure of the wake is displayed. The wind is aligned in the $y$-direction, therefore the distribution of short waves is predominantly aligned in the spanwise direction; hence the primary wave-current interaction occurs along this axis where Bragg-scattering waves interact with the spanwise flow.

For a simulated image with look direction perpendicular to the applied wind, as in 15 Fig. 10a, the structure and flow features as less easily resolved through their contrast with the background NRCS: such details are more visible when the radar look is aligned in a direction with sufficient presence of short waves, e.g. Figure $10 \mathrm{~d}$. In the real ocean, the directionality of short wind waves is likely to be much broader than in this simple case of a uniform wind direction due to spatial variation of both wind speed and direction. Therefore, these results present a "worst-case" state of conditions pertaining to the variation of wake visibility with the instrument look aspect, however it is clear that maximum resolution of the turbulent currents is attainable in cases where strongest interaction with the background wave spectrum occurs.

\subsection{Effect of wind speed}

25 The simulation results obtained thus far represent an idealised case of a turbulent wake produced by a simulated surface vessel moving across a smooth surface of fluid, upon which a spectrum of waves (based on specification of a spatially-invariant wind
OSD

9, 2851-2883, 2012

Measurement of turbulence using SAR

S. G. George and A. R. L. Tatnall

Title Page

Abstract Introduction

Conclusions

Tables

References

Figures

14

$\rightarrow 1$

4

Back

Close

Printer-friendly Version

Interactive Discussion 
field) has been propagated to consider the effects of wave-current interaction on radar backscatter. The dynamics of such a flow in the real ocean will be superposed onto, and interact with, multiple other fluid motions including large-scale currents, orbital wave motions and wave-breaking processes. Furthermore, the ability for SAR to resolve sur5 face features is strongly dependent on the ambient spectrum of backscattering waves (both capillary waves in the Bragg scattering regime and gravity waves causing surface tilting) driven by the characteristics of wind forcing. In the simulations pursued here, the characteristics of the wave spectrum propagated over the simulated wake velocity profile are applied by definition of a simple wind field which is uniform across the domain. 10 In reality, there is likely to be significant spatial variation in wind speed and direction, leading to spatial variation of the waves responsible for backscatter and a departure from the idealised wave-current interaction statistics computed here.

The dependence of wind speed on NRCS is illustrated by the series of plots depicted in Fig. 11, for a region of the turbulent wake beginning approximately $205 \mathrm{~m}$ aft of the 15 location of the simulated surface body and for a uniform wind field aligned in the $y$ direction. Below wind speeds of $2 \mathrm{~ms}^{-1}$, the mean NRCS over the image is typically very low since the weak forcing from the wind typically generates only a meagre distribution of Bragg-scattering waves over the surface. Under such conditions, the low radar response is unlikely to permit the signature to be resolved in a true SAR image. Increasing the simulated wind speed through to medium-level winds ( 2 to $10 \mathrm{~ms}^{-1}$ ) displays a rise in mean image NRCS to levels greater than $-12 \mathrm{~dB}$, and also an increase in mean image contrast (taken as the average contrast across all range lines). At $2 \mathrm{~ms}^{-1}$, there is a mean contrast of approximately $3 \mathrm{~dB}$, while levels this falls below $1 \mathrm{~dB}$ in wind speeds stronger than $8 \mathrm{~ms}^{-1}$, which may lead to insufficient contrast to resolve the signature against the background. A comparison of relative contrast with background NRCS levels (taken in the quiescent fluid outside the wake) at different wind speeds is presented in Fig. 12b for a region of the wake approximately $85-125 \mathrm{~m}$ aft of the body. A representative Bragg NRCS image for wind speed of $4 \mathrm{~m} \mathrm{~s}^{-1}$ is presented in Fig. 12a, along with the location of the cross-wake cuts of NRCS. The transects of
OSD

9, 2851-2883, 2012

Measurement of turbulence using SAR

S. G. George and A. R. L. Tatnall

Title Page
Full Screen / Esc

Printer-friendly Version

Interactive Discussion 
Bragg NRCS in Fig. 12b demonstrate significant variation in the resolved signature with wind speed, particularly under strong winds. These results are consistent with results from a similar sensitivity study published by True et al. (1993), where increasing wind speed leads to a reduction in NRCS perturbation from background levels; although the 5 levels of NRCS perturbation obtained by True et al. (1993) differ in magnitude from those presented due to differences in the numerical model and the radar frequency used in the simulation. Overall, there is indication that the visible radar signature portrayed by the wake turbulence can deteriorate significantly in rough ocean conditions, but that under more modest wind and sea states, the turbulent wake structure may be 10 more easily resolved.

\section{Conclusions}

The results presented here indicate that flow structure embedded in turbulent surface wakes can be translated to and resolved by changes in radar backscatter; in particular, the ability for the currents (and current gradients) associated with small-scale wake 15 turbulence to propagate through the integrated electromagnetic-hydrodynamic wave interaction process into simulated NRCS images. The simulated radar images of smallscale upper-ocean turbulence presented in this paper are consistent with existing SAR observations of turbulent surface wakes that display a reduction of NRCS inside the turbulent wake region due to turbulent surface currents.

20 Numerical experiments of a simulated radar instrument were performed for a range of ambient conditions and for a number of instrument configurations. These have shown that, where there is observable and interesting flow structure present in the wake, this structure can be translated through the modelling process into modulated NRCS imagery. There is encouraging potential for successful observation of such turbulent phenomena with future developments in SAR instrumentation. The surface profiles of velocity from the DNS process, and the modulated NRCS observed when processing these profiles through integrated hydrodynamic-electromagnetic wave interaction
OSD

9, 2851-2883, 2012

Measurement of turbulence using SAR

S. G. George and A. R. L. Tatnall

Title Page

Abstract Introduction

Conclusions

Tables

References

Figures

14

$>1$

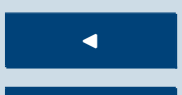

Back

Close

Full Screen / Esc

Printer-friendly Version

Interactive Discussion 
models, were found to be consistent with similar data recently presented by Fujimura et al. (2011) and with SAR ship wakes published in the literature. Currently there are limited SAR observations of small-scale turbulence primarily due to the limitations of spatial resolution from typical spaceborne instruments: the grid resolution of 5 the modulated NRCS profiles shown here are around $15 \mathrm{~cm}$, while typical SARs such as TerraSAR-X and Envisat ASAR can achieve typical resolutions of $3 \mathrm{~m} \times 3 \mathrm{~m}$ and $12.5 \mathrm{~m} \times 12.5 \mathrm{~m}$. When averaged to similar resolutions, the turbulence NRCS signatures may deteriorate significantly and reduce the capability to observe small-scale structure. Motion of the surface and platform during generation of a real SAR image 10 may also introduce further issues which degrade the ability. However, despite the current results being preliminary, there is sufficient indication of the feasibility of measuring turbulence with SAR in the context of future developments of spatial resolution, sensitivity and noise reduction. The techniques developed here provide a tool for optimizing measurement techniques and parameters, indicating the necessary requirements to 15 observe small-scale turbulence in the upper ocean. They also provide a better understanding of the relationship between turbulence and radar cross-section that could enable turbulence and sources to be characterised.

These efforts have shown the ability of ocean radar image modelling to convert turbulent wake results from a primitive DNS model into encouraging results that resolve components of the flow structure in simulated Bragg NRCS and SAR imagery. This shows promise for using SAR to investigate and observe near-surface turbulence, and may aid in revealing methods by which improvements in observation of the flow structure of turbulent wake flows can be accomplished. However, further work is required to develop these relationships, and to understand the impact of surface-layer turbulence on radar backscattering through imaging models under a range of ambient and observation conditions, turbulent processes and operational constraints.

A crucial element for the future development of these results is to investigate the important relationship between turbulence in the upper ocean layer and air-sea exchange processes, and to examine the feasibility of quantifying the impacts of such
OSD

9, 2851-2883, 2012

Measurement of turbulence using SAR

S. G. George and A. R. L. Tatnall

Title Page 
exchanges through remote-sensing measurements. Further study may identify the potential to extract characteristics of turbulence dissipation or vorticity from simulated remote measurements and apply relations between such values and empirical gas exchange relationships, such as that between gas transfer rate and dissipation of Tur5 bulence Kinetic Energy (TKE) discussed by Zappa et al. (2007). Alternatively, there may be possibilities for estimating energy and momentum fluxes from the structure of flow in the upper ocean which may be observed using SAR: turbulent flows at the surface could help quantify the effect of surface renewal processes which are important in estimating air-sea exchanges, as discussed by, e.g. Komori and Ueda (1982) and 10 Banerjee and Maclntyre (2004). Comparisons may be drawn between the simulation process constructed in this study, and similar numerical simulations of turbulence at the ocean-atmosphere interface using DNS and LES (Large Eddy Simulation) and relationships with gas exchange, for example Banerjee and MacIntyre (2004) and Shen and Yue (2006). Improving observation of subsurface processes in the oceanic mixed layer on a global scale will increase our understanding of the uptake of heat and $\mathrm{CO}_{2}$ by the ocean, and improve parameterisation of the fluxes associated with air-sea exchange.

Acknowledgements. The authors would like to thank Watchapon Rojanaratanangkule, Gary Coleman and Glyn Thomas at the University of Southampton for their assistance and expertise in running the DNS code and supplying the ship wake data. Further thanks go to Roland

20 Romeiser of the University of Miami for use of the radar imaging model used in this study and stimulating discussion regarding results. The authors acknowledge the use of the IRIDIS High Performance Computing Facility at the University of Southampton in the completion of this research. This work was performed as part of an ongoing Ph.D. project titled "Satellite Measurement of Ocean Turbulence" funded by the University of Southampton and the Engineering 25
OSD

9, 2851-2883, 2012

Measurement of turbulence using SAR

S. G. George and A. R. L. Tatnall

Title Page

Abstract Introduction

Conclusions

References

Tables Figures

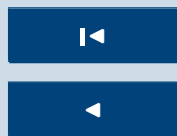

$>1$

Back

Close

Printer-friendly Version

Interactive Discussion 


\section{References}

Alpers, W. R., Campbell, G., Wensink, H., and Zhang, Q.: Underwater topography, in: SAR Marine User's Manual, edited by: Jackson, C. R. and Apel, J. R., National Oceanic and Atmospheric Administration, Washington DC, USA, 245-262, 2004, available at: http://www. sarusersmanual.com/, last access: 15 May 2012.

Archer, P. J.: A Numerical Study of Laminar to Turbulent Evolution and Free-Surface Interaction of a Vortex Ring, Ph. D. thesis, University of Southampton, Southampton, UK, 2008.

Banerjee, S. and MacIntyre, S.: The air-water interface: Turbulence and scalar exchange, in: Advances in Coastal and Ocean Engineering vol. 9: PIV and Water Waves, edited by: Grue, J.,

10 Liu, P. L. F. and Pedersen, G. K., World Scientific, Singapore, 181-237, 2004.

Chubb, S. R., Askari, F., Donato, T. F., Romeiser, R., Ufermann, S., Cooper, A. L., Alpers, W. R., and Mango, S. A.: Study of Gulf Stream features with a multifrequency polarimetric SAR from the Space Shuttle, IEEE Trans. Gisci. Remote Sens., 37, 2495-2507, 1999.

Fujimura, A., Matt, S., Soloviev, A., Maingot, C., and Rhee, S. H.: The Impact of Thermal Stratification and Wind Stress on Sea Surface Features in SAR Imagery, IGARSS2011 IEEE Geoscience and Remote Sensing Symposium, Vancouver BC, Canada, 24-29 July 2011, 2037-2040, 2011.

Hennings, I., Romeiser, R., Alpers, W. R., and Viola, A.: Radar imaging of Kelvin arms of ship wakes, Int. J. Remote Sens., 20, 2519-2543, 1999.

20 Ivanov, A. Y. and Ginzburg, A. I.: Oceanic eddies in synthetic aperture radar images, J. Earth Syst. Sci., 111, 281-295, doi:10.1007/BF02701974, 2002.

Johannessen, J. A., Kudryavtsev, V. N., Akimov, D., Eldevik, T., Winther, N., and Chapron, B.: On radar imaging of current features: 2 . Mesoscale eddy and current front detection, J. Geophys. Res., 110, 1-14, doi:10.1029/2004JC002802, 2005.

25 Khatiwala, S., Primeau, F., and Hall, T.: Reconstruction of the history of anthropogenic $\mathrm{CO}_{2}$ Concentrations in the Ocean, Nature, 462, 346-350, doi:10.1038/nature08526, 2009.

Kitaigorodskii, S. A. and Lumley, J. L.: Wave-turbulence interactions in the upper ocean. Part I: The energy balance of the interacting fields of surface wind waves and wind-induced threedimensional turbulence, J. Phys. Oceanogr., 13, 1977-1987, 1983.

30 Kitaigorodskii, S. A., Donelan, M., Lumley, J. L., and Terray, E. A.: Wave-turbulence interactions in the upper ocean. Part II: Statistical characteristics of wave and turbulent components of
OSD

9, 2851-2883, 2012

Measurement of

turbulence using

SAR

S. G. George and

A. R. L. Tatnall

Title Page

Abstract

Introduction

Conclusions

References

Tables

Figures

14

4

Back

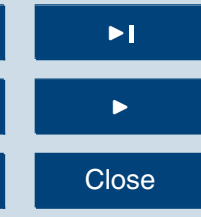

Full Screen / Esc

Printer-friendly Version

Interactive Discussion 
the random velocity field in the marine surface layer, J. Phys. Oceanogr., 13, 1988-1999, 1983.

Komori, S., Ueda, H., Ogino, F., and Mizushina, T.: Turbulence structure and transport mechanism at the free surface in an open channel flow, Int. J. Heat Mass Tran., 25, 513-521, 51982.

LeBlond, P. H. and Mysak, L. A.: Waves in the Ocean, Elsevier Science Publishers, Norwich, UK, 1978.

Lyden, J. D., Lyzenga, D. R., Shuchman, R. A., and Swanson, C. V.: SAR Detection of ShipGenerated Turbulent and Vortex Wakes, Tech. Memo. RR-86-112, Environmental Research Institute of Michigan, Ann Arbor MI, USA, 1985.

Lyden, J. D., Hammond, R., Lyzenga, D. R., and Shuchman, R. A.: Synthetic aperture radar imaging of surface ship wakes, J. Geophys. Res., 93, 12293-12303, 1988.

McKenna, S. P.: Free-Surface Turbulence and Air-Water Gas Exchange, Ph. D. thesis, Massachusetts Institute of Technology/Woods Hole Oceanographic Institution, Boston/Woods 15 Hole MA, USA, 2000.

McKenna, S. P. and McGillis, W. R.: The role of free-surface turbulence and surfactants in airwater gas transfer, Int. J. Heat Mass Tran., 47, 539-553, 2004.

Milgram, J. H., Skop, R. A., Peltzer, R. D., and Griffin, O. M.: Modeling short sea wave energy distributions in the far wakes of ships, J. Geophys. Res., 98, 7115-7124, 20 doi:10.1029/92JC02611, 1993

Munk, W. H., Scully-Power, P., and Zachariasen, F.: Ships from Space, in: Proceedings of the Royal Society A: Mathematical, Physical and Engineering Sciences, 412, 231-254, 1987.

Ölmez, H. S. and Milgram, J. H.: An experimental study of attenuation of short water waves by turbulence, J. Fluid Mech., 239, 133-156, 1992.

Phillips, O. M., Batchelor G. K., and Miles, J. W. (Eds.): The Dynamics of the Upper Ocean, Cambridge University Press, Cambridge, UK, 1966.

Reed, A. M. and Milgram, J. H.: Ship wakes and their radar images, Annu. Rev. Fluid Mech., 34, 469-502, doi:10.1146/annurev.fluid.34.090101.190252, 2002.

Reed, A. M., Beck, R. F., Griffin, O. M., and Peltzer, R. D.: Hydrodynamics of remotely sensed surface ship wakes, SNAME Transactions, 98, 319-363, 1990.

Romeiser, R. and Alpers, W. R.: An improved composite surface model for the radar backscattering cross section of the ocean surface 2 . Model response to surface roughness variations

OSD

9, 2851-2883, 2012

Measurement of

turbulence using

SAR

S. G. George and

A. R. L. Tatnall

Title Page

Abstract

Introduction

Conclusions

References

Tables

Figures

14

4

Back

Close

Full Screen / Esc

Printer-friendly Version

Interactive Discussion

\section{$\Delta$}

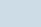
sion 
and the radar imaging of underwater bottom topography, J. Geophys. Res., 102, 2525125267, doi:10.1029/97JC00191, 1997.

Romeiser, R., Alpers, W. R., and Wismann, V.: An improved composite surface model for the radar backscattering cross section of the ocean surface 1. Theory of the model and optimization/validation by scatterometer data, J. Geophys. Res., 102, 25237-25250, doi:10.1029/97JC00190, 1997.

Sabine, C. L., Feely, R. A, Gruber, N., Key, R. M., Lee, K., Bullister, J. L., Wanninkhof, R., Wong, C. S., Wallace, D. W. R., Tilbrook, B., Millero, F. J., Peng, T.-H., Kozyr, A., Ono, T., and Rios, A. F.: The oceanic sink for anthropogenic $\mathrm{CO}_{2}$, Science, 305, 367-371, doi:10.1126/science.1097403, 2004.

Shen, L. and Yue, D. K. P.: Using computer simulations to help understand flow statistics and structures, Oceanography, 19, 52-63, 2006.

Soloviev, A., Donelan, M., Graber, H. C., Haus, B., and Schlussel, P.: An approach to estimation of near-surface turbulence and $\mathrm{CO}_{2}$ transfer velocity from remote sensing data, J. Marine 15 Syst., 66, 182-194, doi:10.1016/j.jmarsys.2006.03.023, 2007.

Soloviev, A., Maingot, C., Fujimura, A., Fenton, J., Gilman, M., Matt, S., Lehner, S., Velotto, D., and Brusch, S.: Fine Structure of the Upper Ocean from High-Resolution TerraSAR-X Imagery and In-Situ Measurements, IGARSS2010 IEEE Geoscience and Remote Sensing Symposium, Honolulu HI, USA, 25-30 July 2010, 1944-1947, 2010.

20 Thomas, T. G. and Williams, J. J. R.: Development of a parallel code to simulate skewed flow over a bluff body, J. Wind Eng. Ind. Aerod., 67-68, 155-167, doi:10.1016/S01676105(97)00070-6, 1997.

Thompson, D. R.: Intensity modulations in synthetic aperture radar images of ocean surface currents and the wave/current interaction process, in: John Hopkins APL Technical Digest, 6(4), 1985.

Toporkov, J. V., Hwang, P. A., Sletten, M. A., Farquharson, G., Perkovic, D., and Frasier, S. J.: Surface velocity profiles in a vessel's turbulent wake observed by a dual-beam along-track interferometric SAR, IEEE Geosci. Remote S. Lett., 8, 602-606, 2011.

True, M. A., Lyzenga, D. R., and Lyden, J. D.: Centreline Wake Modeling, Final Report 2075008-T, Environmental Research Institute of Michigan, Ann Arbor MI, USA, 1993.

Veron, F., Melville, W. K., and Lenain, L.: The effects of small-scale turbulence on air-sea heat flux, J. Phys. Oceanogr., 41, 205-220, doi:10.1175/2010JPO4491.1, 2011.

\section{OSD}

9, 2851-2883, 2012

Measurement of turbulence using SAR

S. G. George and A. R. L. Tatnall

Title Page

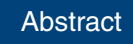

Introduction

Conclusions

References

Tables

Figures

14

4

Back

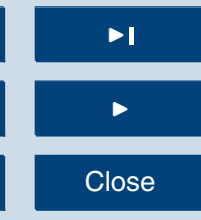

Full Screen / Esc

Printer-friendly Version

Interactive Discussion 
Wright, J. W.: A new model for sea clutter, IEEE T. Antenn. Propag., 16, 217-223, doi:10.1109/TAP.1968.1139147, 1968.

Zappa, C. J., McGillis, W. R., Raymond, P. A., Edson, J. B., Hintsa, E. J., Zemmelink, H. J., Dacey, J. W. H., and Ho, D. T.: Environmental turbulent mixing controls on air-water gas exchange in marine and aquatic systems, Geophys. Res. Lett., 34, 10601, doi:10.1029/2006GL028790, 2007.

Zappa, C. J., Ho, D. T., McGillis, W. R., Banner, M. L., Dacey, J. W. H., Bliven, L. F., Ma, B., and Nystuen, J.: Rain-induced turbulence and air-sea gas transfer, J. Geophys. Res., 114, 1-17, doi:10.1029/2008JC005008, 2009.

OSD

9, 2851-2883, 2012

\section{Measurement of turbulence using SAR}

S. G. George and A. R. L. Tatnall

Title Page

Abstract Introduction

Conclusions

References

Tables

Figures

14

4

Back

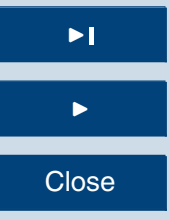

Full Screen / Esc

Printer-friendly Version

Interactive Discussion 


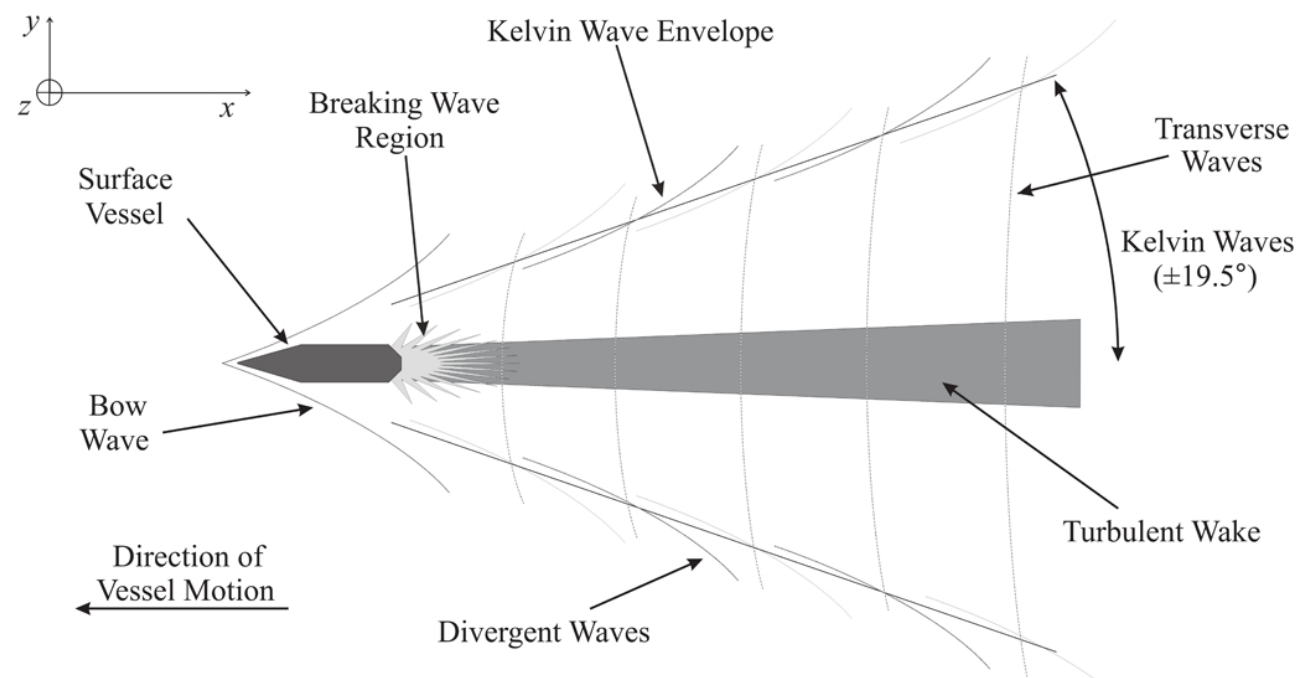

OSD

$9,2851-2883,2012$

\section{Measurement of turbulence using SAR}

S. G. George and A. R. L. Tatnall

Title Page

Abstract Introduction

Conclusions

References

Tables

Figures

Fig. 1. Schematic of a typical turbulent ship wake as viewed by SAR.

Printer-friendly Version

Interactive Discussion

\section{Full Screen / Esc}

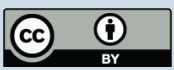




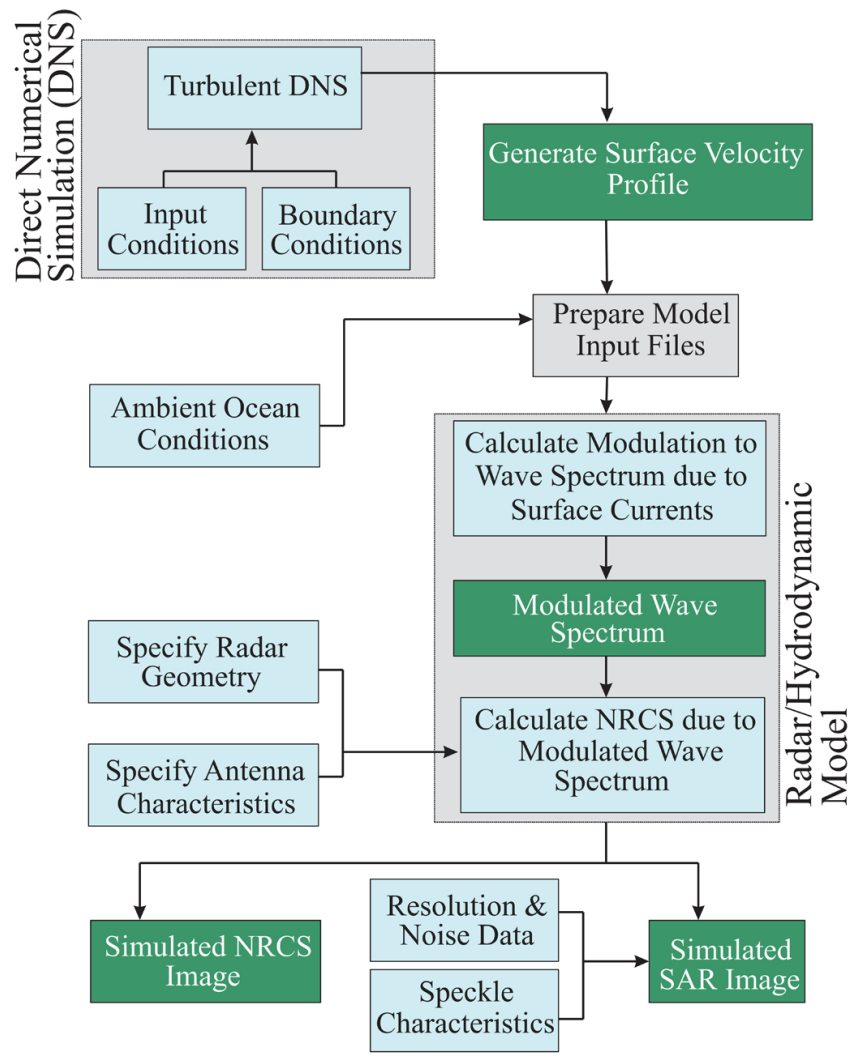

OSD

9, 2851-2883, 2012

Measurement of turbulence using SAR

S. G. George and A. R. L. Tatnall

Title Page

Abstract

Introduction

Conclusions

References

Tables

Figures

14

- I

4

Back

Close

Full Screen / Esc

Fig. 2. The simulation strategy applied in this case study to simulate remote-sensing SAR signature of near-surface ocean turbulence embedded in the wake of a surface moving body.

Printer-friendly Version

Interactive Discussion 


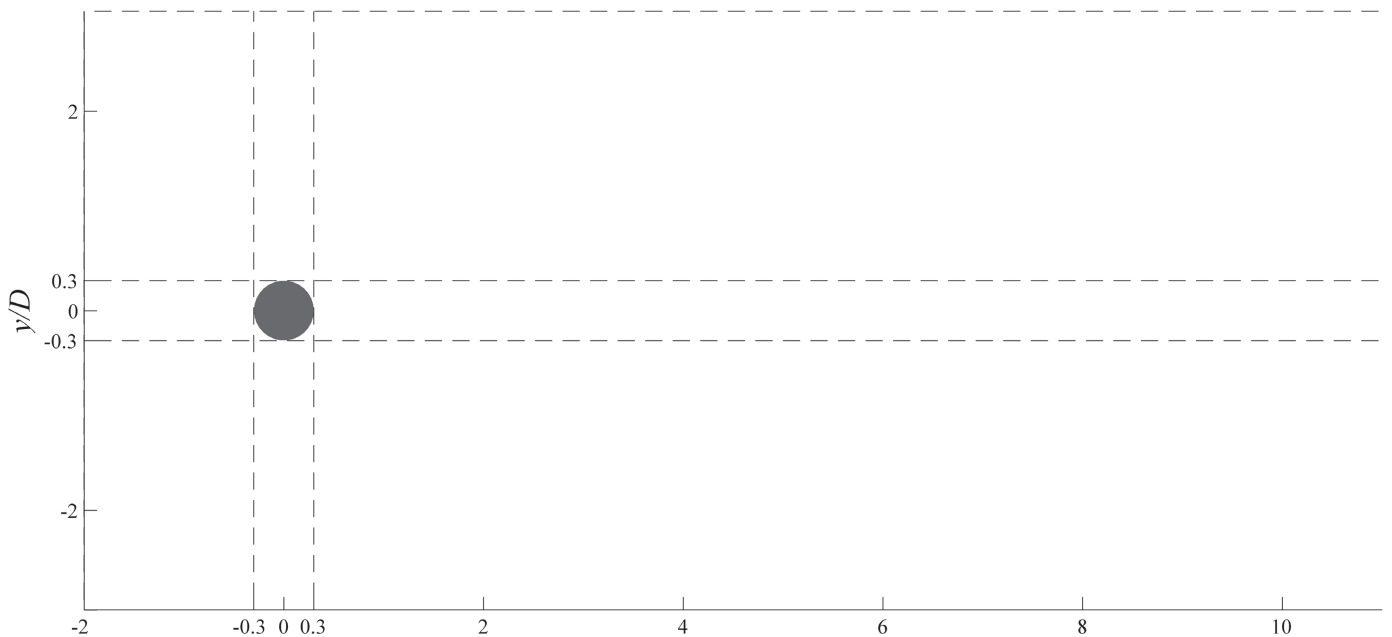

\section{9, 2851-2883, 2012}

\section{Measurement of turbulence using SAR}

S. G. George and A. R. L. Tatnall

Title Page

(b)

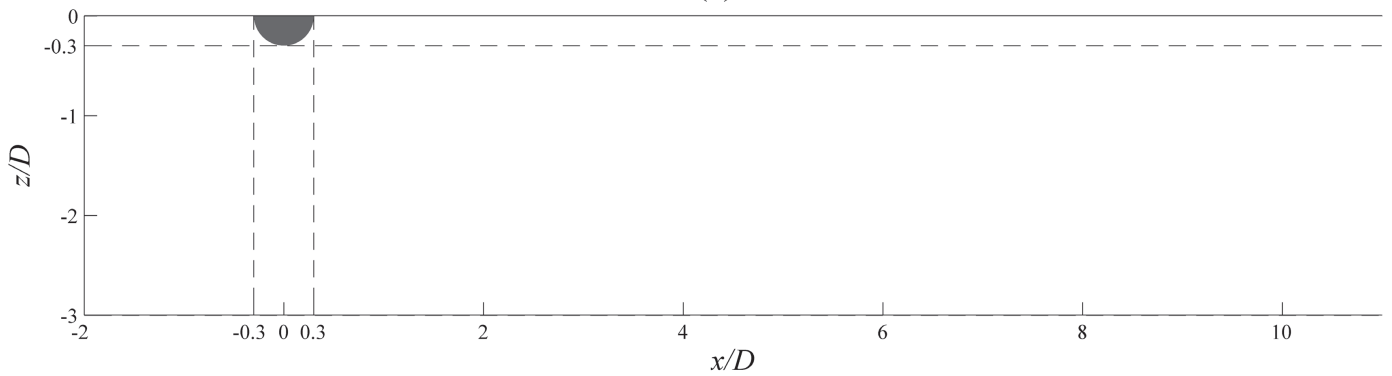

Introduction

Conclusions

References

Tables

Figures

14

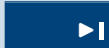

4

Back

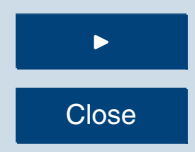

Full Screen / Esc

Fig. 3. Parameterisation of half-sphere body force in the turbulent DNS, from (a) top-down view, and (b) side views. D is a length scale parameter associated with the scale of the body force (diameter 0.3-D) used to non-dimensionalise the domain.

Printer-friendly Version

Interactive Discussion 
(a)

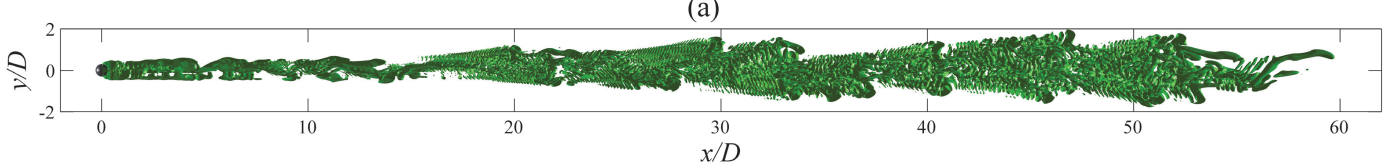

(b)

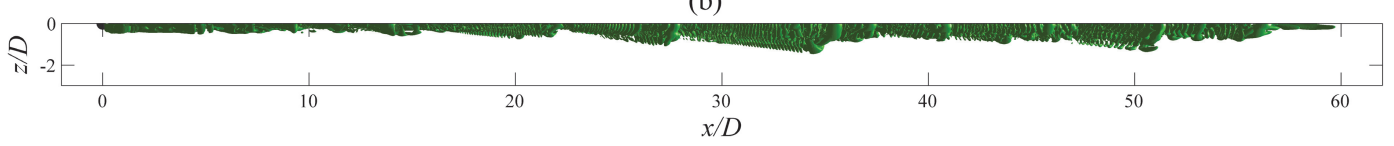

Fig. 4. Example plot of DNS-originated turbulent wake, showing an isosurface of the second invariant of the velocity gradient tensor (II), from (a) top-down view and (b) side views.
OSD

9, 2851-2883, 2012

Measurement of turbulence using SAR

S. G. George and A. R. L. Tatnall

Title Page

Abstract

Introduction

Conclusions

References

Tables

Figures

14

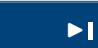

4

Back

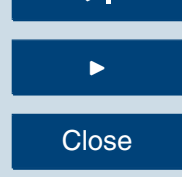

Full Screen / Esc

Printer-friendly Version

Interactive Discussion 

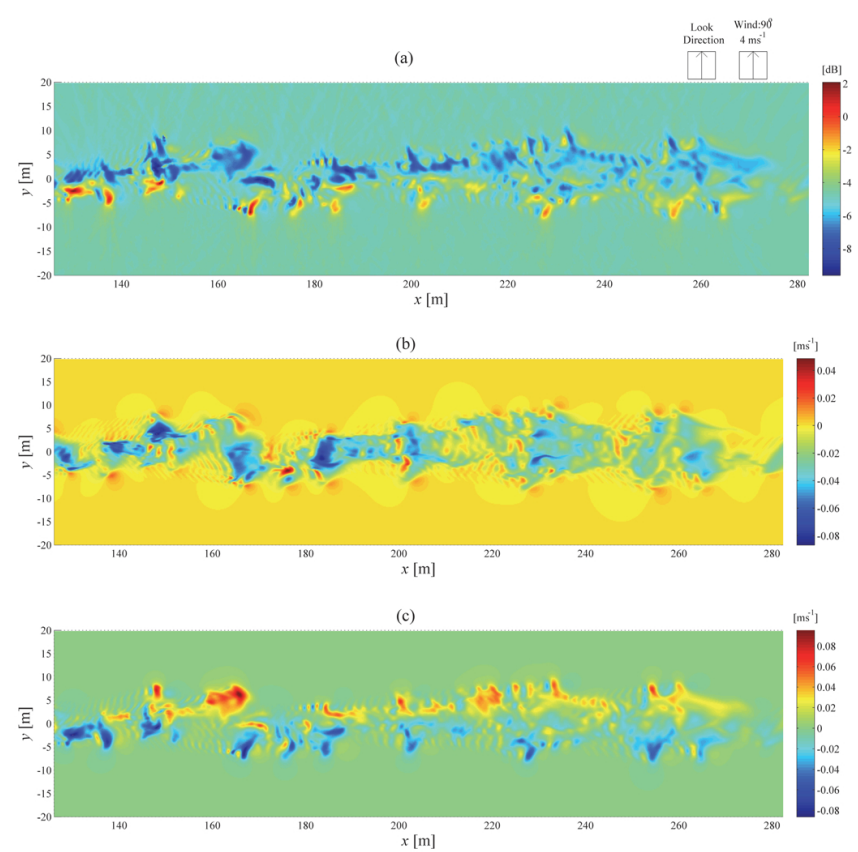

Title Page

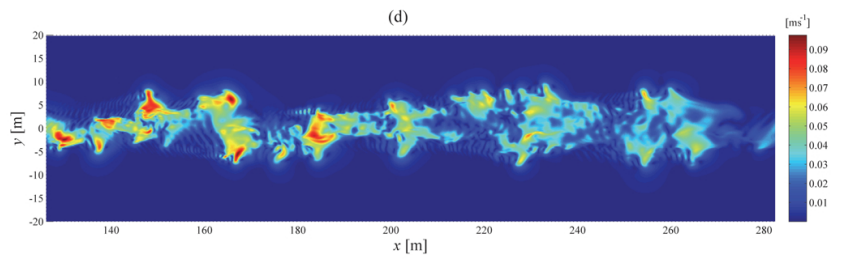

Fig. 5. Comparison of turbulent structure observed in (a) composite spectrum NRCS image at $5.3 \mathrm{GHz}$ (C-band), $\mathrm{HH}$-polarisation and $23^{\circ}$ incidence angle, and input profiles of (b) $u$-velocity (streamwise), (c) $v$-velocity (spanwise) and (d) magnitude of velocity at a region of the wake commencing $130 \mathrm{~m}$ aft of the vessel. The units of NRCS are presented in decibels (dB), where values are equal to $10 \log _{10}\left(\sigma_{0}\right)$.

Measurement of turbulence using SAR

S. G. George and A. R. L. Tatnall

Abstract

Conclusions

Tables

References

Figures

14

4

Back

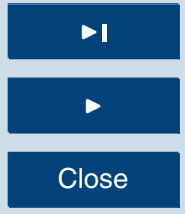

Full Screen / Esc

Printer-friendly Version

Interactive Discussion 

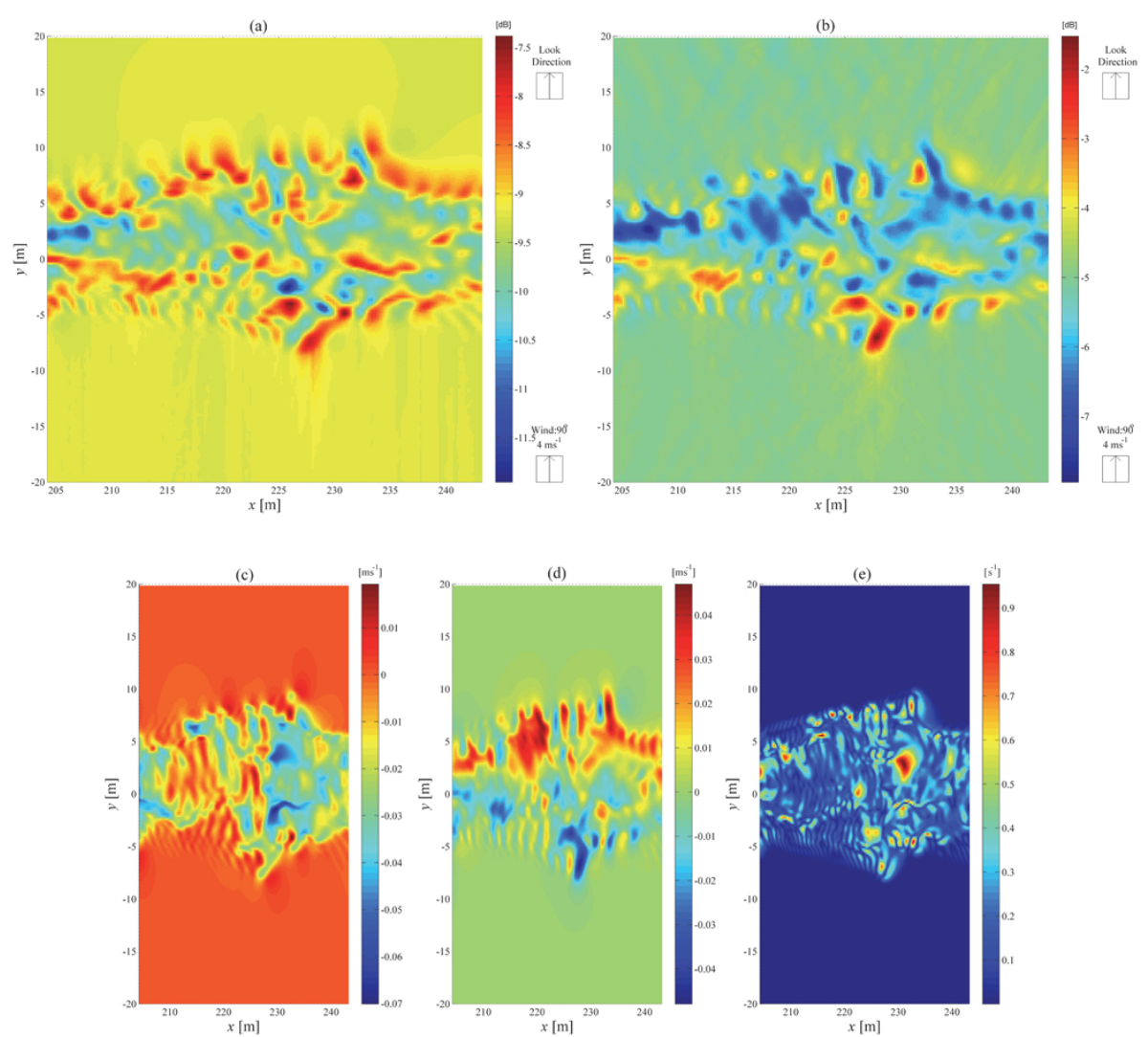

Fig. 6. Comparison of visual structure in the simulated NRCS profile and surface fluid characteristics for a region of the wake approximately $205 \mathrm{~m}$ aft of the surface vessel for instrument operating at $5.3 \mathrm{GHz}$ (C-band), $\mathrm{HH}$-polarisation and $23^{\circ}$ incidence angle: (a) Bragg NRCS; (b) composite spectrum NRCS; (c) surface $u$-velocity; (d) surface $v$-velocity; (e) total surface vorticity.

\section{OSD}

9, 2851-2883, 2012

Measurement of turbulence using SAR

S. G. George and A. R. L. Tatnall

Title Page

Abstract

Conclusions

\section{Tables}

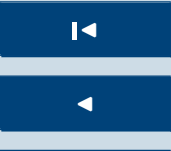

Back

\section{Full Screen / Esc}

Printer-friendly Version

Interactive Discussion 

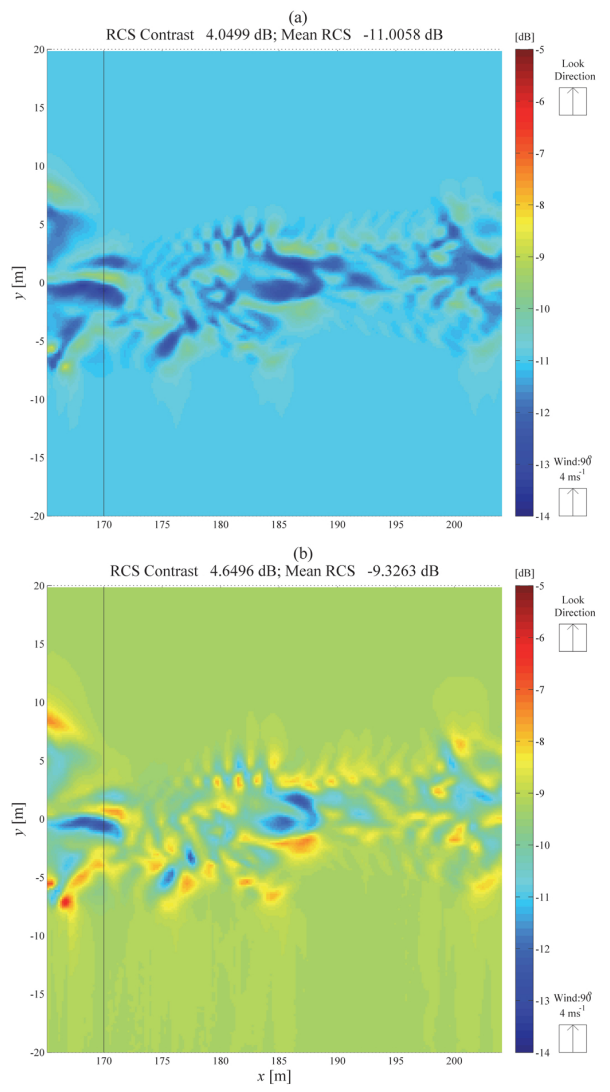

Fig. 7. Variation of Bragg NRCS visual structure and simulated operating frequency for a region of the wake approximately $165 \mathrm{~m}$ aft of the surface vessel for instrument operating at $\mathrm{HH}$ polarisation and $23^{\circ}$ incidence angle: (a) $9.6 \mathrm{GHz}$ (X-band); (b) $5.3 \mathrm{GHz}$ (C-band). Contrast is defined as the maximum range of NRCS along the transect shown at $170 \mathrm{~m}$.
OSD

$9,2851-2883,2012$

Measurement of turbulence using

SAR

S. G. George and A. R. L. Tatnall

Title Page

Abstract

Introduction

Conclusions

References

Tables

Figures

14

$\Delta$

4

Back

Close

Full Screen / Esc

Printer-friendly Version

Interactive Discussion 


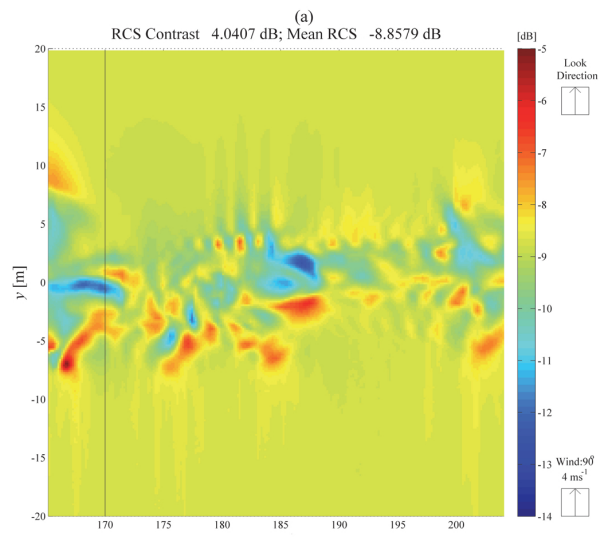

OSD

9, 2851-2883, 2012

Measurement of turbulence using

SAR

S. G. George and A. R. L. Tatnall

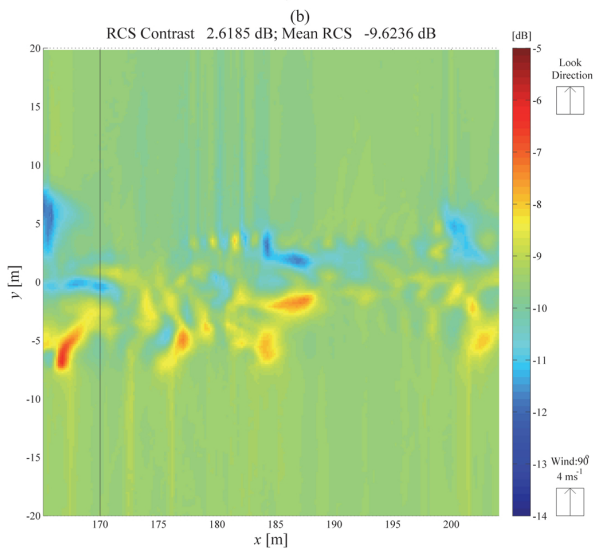

Title Page

Abstract

Introduction

Conclusions

References

Tables

Figures

14

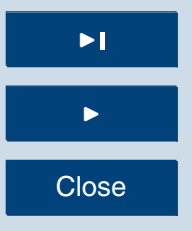

Back

Close

Full Screen / Esc

Fig. 8. Variation of NRCS visual structure and simulated operating frequency for a region of the wake approximately $165 \mathrm{~m}$ aft of the surface vessel for instrument operating at $\mathrm{HH}$-polarisation and $23^{\circ}$ incidence angle: (a) $3.2 \mathrm{GHz}$ (S-band); (b) $1.2 \mathrm{GHz}$ (L-band). Contrast is defined as the maximum range of NRCS along the transect shown at $170 \mathrm{~m}$.

Printer-friendly Version

Interactive Discussion 


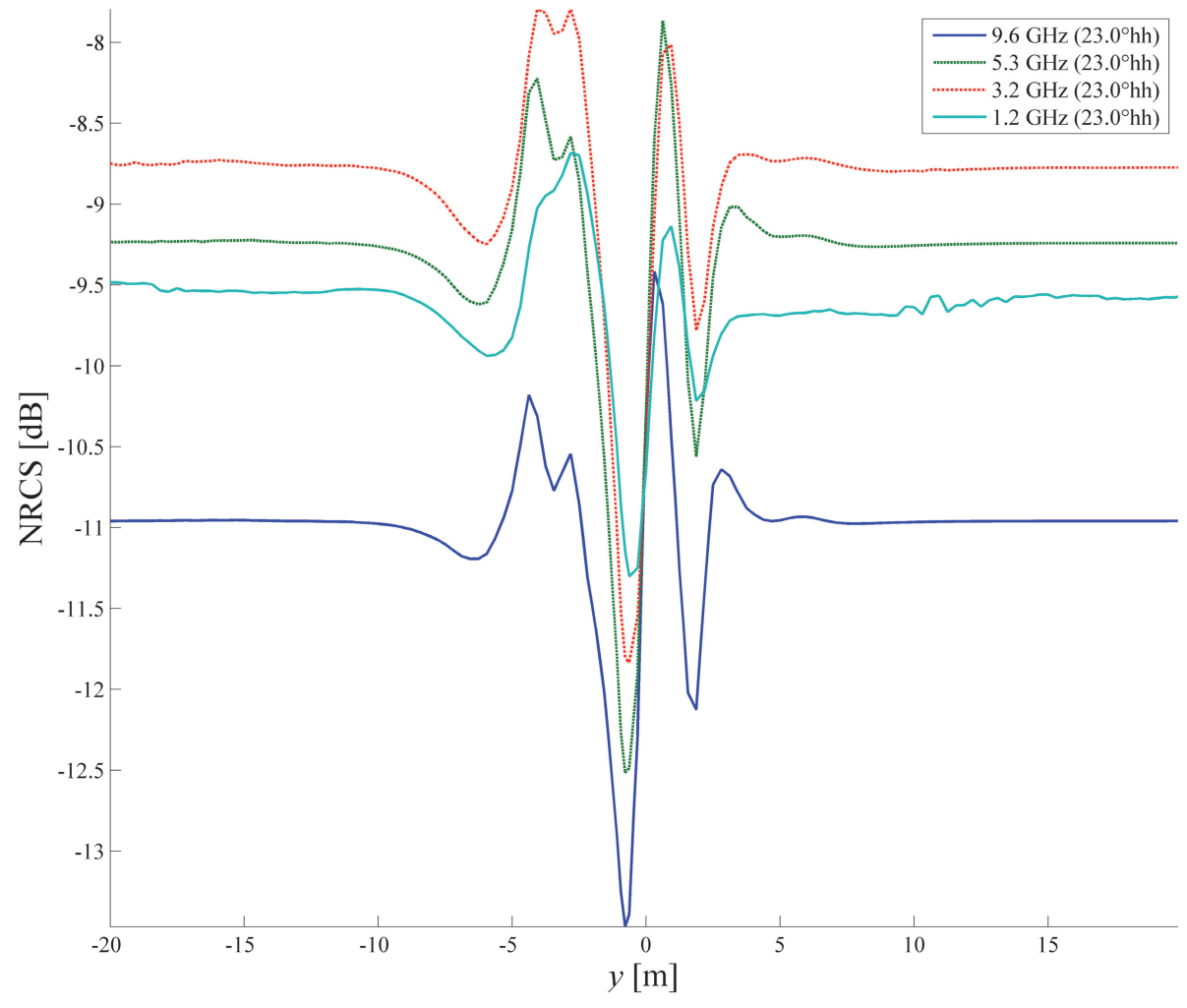

Fig. 9. Variation of NRCS visual structure and simulated operating frequency along a transect of Bragg NRCS taken approximately $165 \mathrm{~m}$ aft of the surface vessel for X-, C-, S- and L-band instruments operating at $\mathrm{HH}$-polarisation and $23^{\circ}$ incidence angle.
OSD

9, 2851-2883, 2012

\section{Measurement of turbulence using SAR}

S. G. George and A. R. L. Tatnall

Title Page

Abstract Introduction

Conclusions

References

Tables

Figures

14

4

Back

Close

Full Screen / Esc

Printer-friendly Version

Interactive Discussion 


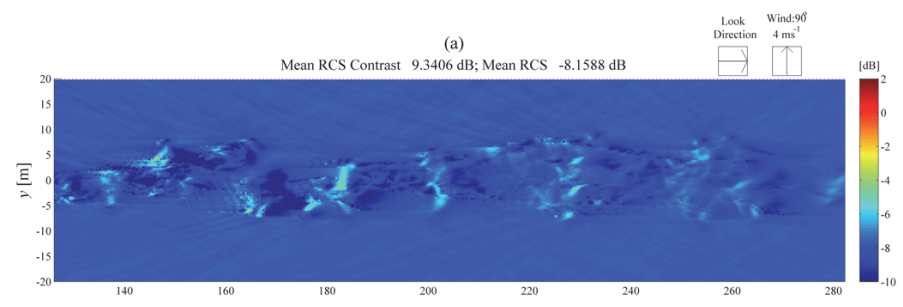

OSD

9, 2851-2883, 2012

Measurement of turbulence using SAR

S. G. George and A. R. L. Tatnall

Title Page
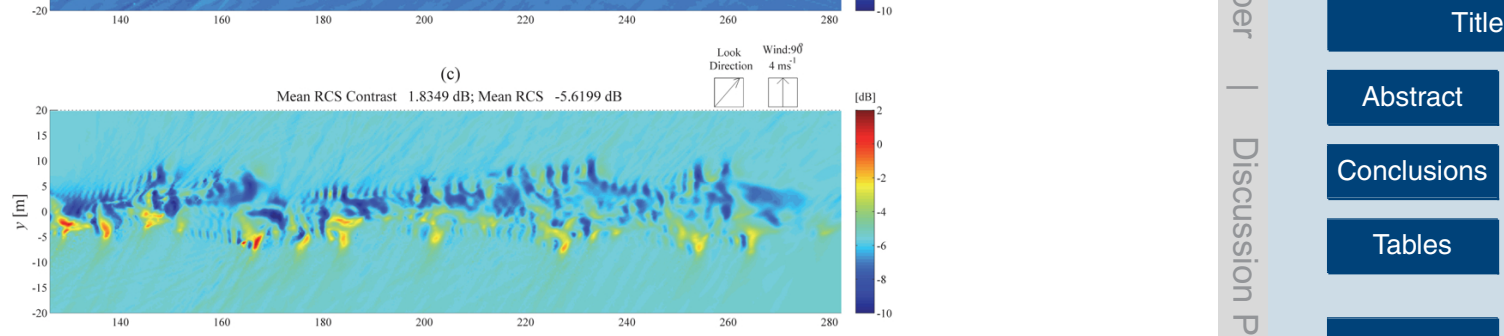

Introduction

Conclusions

References

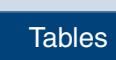

Figures

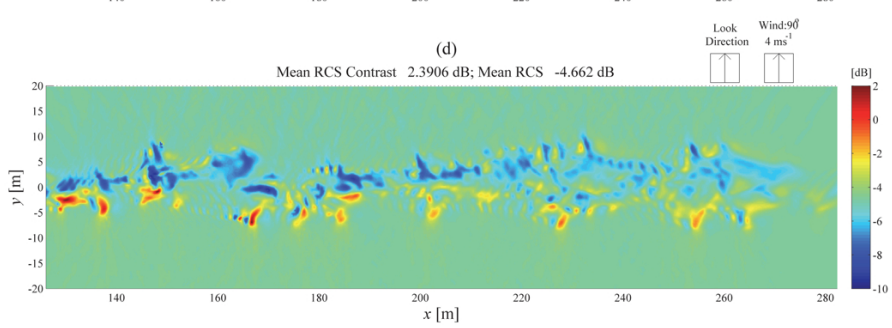

Fig. 10. Variation in look direction of a $5.3 \mathrm{GHz}$ (C-band) radar operating at $\mathrm{HH}$-polarisation and $23^{\circ}$ incidence angle from (a) $0^{\circ}$ with respect to the x-axis, (b) $30^{\circ}$, (c) $60^{\circ}$, (d) $90^{\circ}$.

\section{Back}

Full Screen / Esc

Printer-friendly Version

Interactive Discussion 

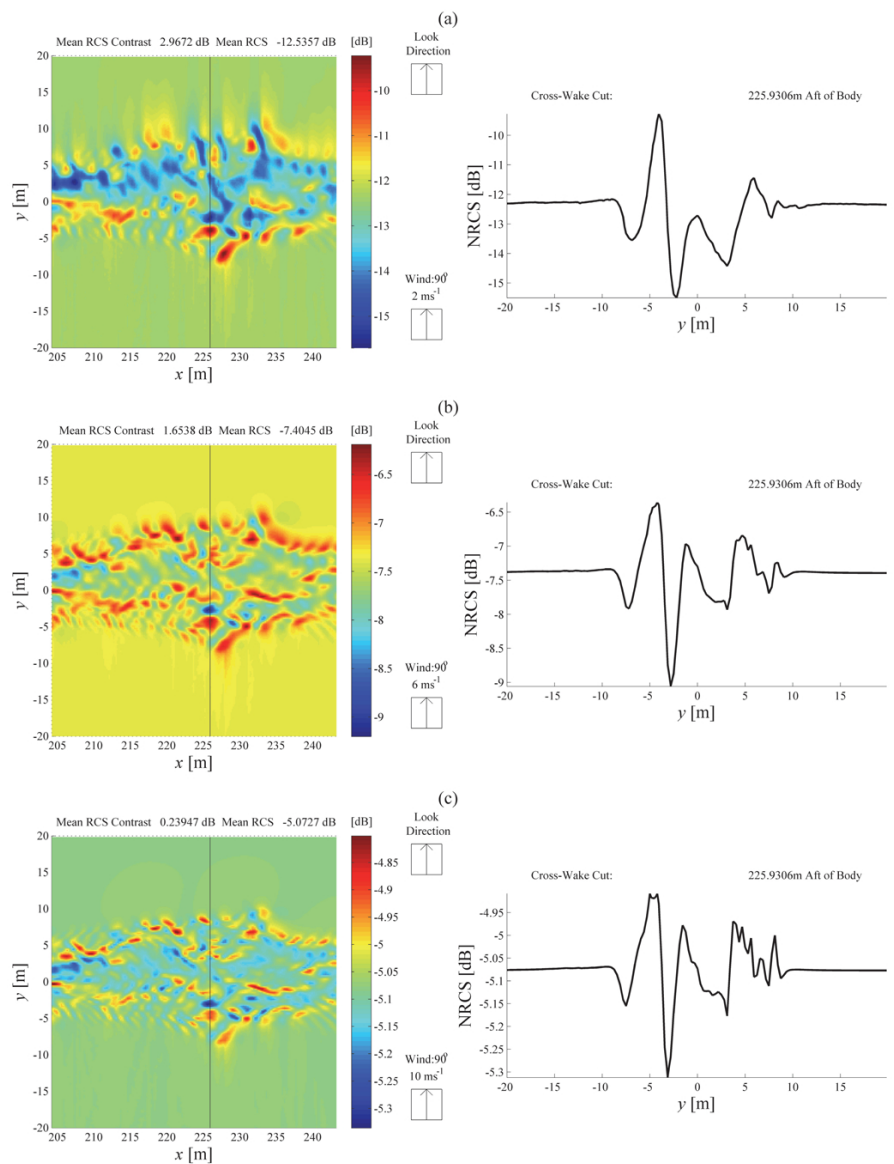

Fig. 11. Effect of wind speed on Bragg NRCS for a simulated $5.3 \mathrm{GHz}$ (C-band) radar with $\mathrm{HH}$ polarisation and $23^{\circ}$ incidence angle for (a) $2 \mathrm{~m} \mathrm{~s}^{-1}$, (b) $6 \mathrm{~m} \mathrm{~s}^{-1}$, (c) $10 \mathrm{~m} \mathrm{~s}^{-1}$ uniform wind fields aligned with the $y$-axis.
OSD

9, 2851-2883, 2012

Measurement of turbulence using SAR

S. G. George and A. R. L. Tatnall

Title Page

Abstract Introduction

Conclusions

References

Tables

Figures

14

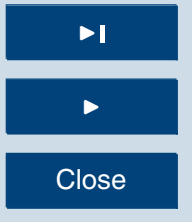

Back

Full Screen / Esc

Printer-friendly Version

Interactive Discussion 

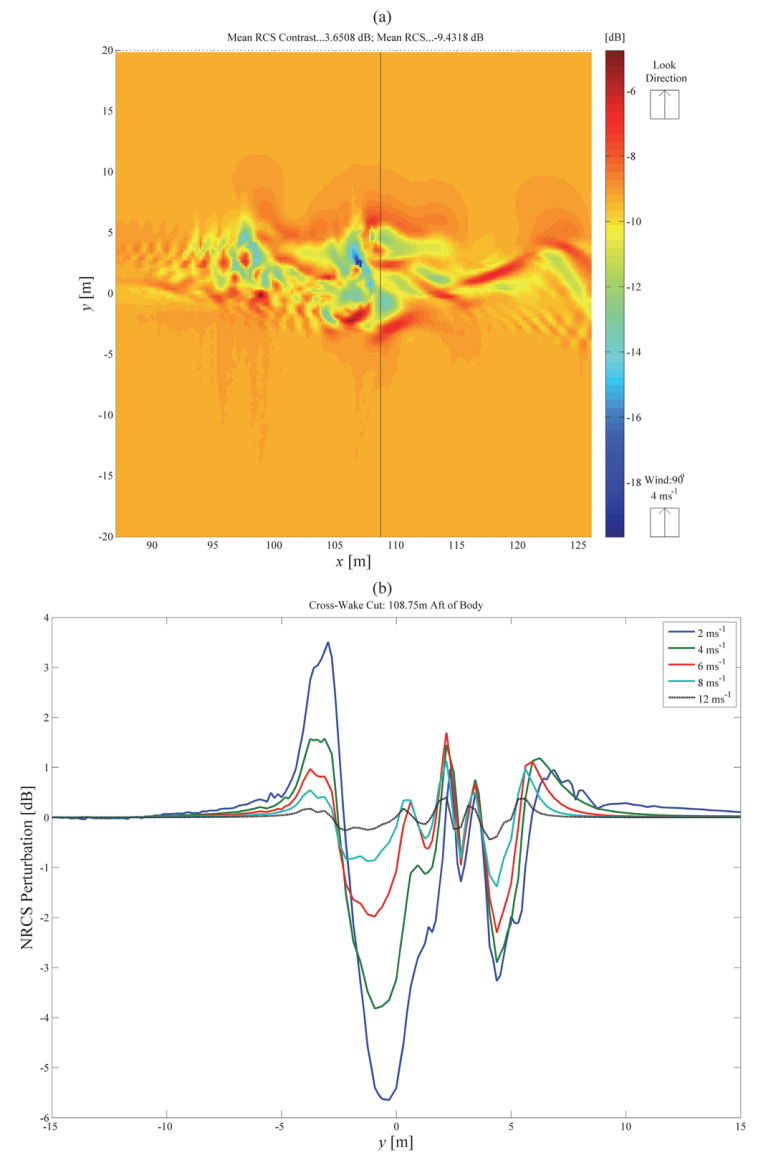

Title Page

Abstract

Introduction

Conclusions

References

Tables

Figures

14

4

Back

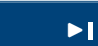

I

\section{Full Screen / Esc}

Fig. 12. Variation of relative Bragg NRCS perturbation (contrast of signature with background) with wind speeds $2-12 \mathrm{~ms}^{-1}$ applied in the $y$-direction for a simulated $5.3 \mathrm{GHz}$ (C-band) radar with $\mathrm{HH}$-polarisation and $23^{\circ}$ incidence angle. 